CONCISE REPORT

\title{
Grey scale and power Doppler sonographic changes induced by intra-articular steroid injection treatment
}

\author{
E Filippucci, A Farina, M Carotti, F Salaffi, W Grassi
}

Ann Rheum Dis 2004;63:740-743. doi: 10.1136/ard.2003.007971

Objective: To investigate the ability of high resolution grey scale sonography (GSS) and power Doppler sonography (PDS) to assess short term soft tissue changes induced by intra-articular steroid injection in the small joints of patients with chronic synovitis.

Methods: 20 patients with clinically active synovitis of a small joint unresponsive to systemic drug treatment underwent a sonographic guided intralesional injection with triamcinolone acetonide. Clinical examinations were carried out by a trained rheumatologist. GSS and PDS examinations were performed independently by two examiners unaware of the results of the clinical examination. Joint cavity widening and power Doppler signal were evaluated and graded on a semiquantitative scale ranging from 1 to 4 . Clinical and sonographic follow up examinations were carried out 2 weeks after the injection with triamcinolone acetonide.

Results: All intra-articular injections were successfully carried out and documented under sonographic guidance. In 19/20 patients, baseline sonographic examinations clearly detected morphological and perfusional signs of synovitis. At follow up examinations, clinical and sonographic scores had improved significantly.

Conclusion: GSS and PDS appear to be a useful adjunctive tool for assessing short term soft tissue changes induced by intra-articular injection treatment with triamcinolone acetonide in small joints of patients with chronic arthritis.

O ver the past 10 years, high resolution grey scale ultrasonography (GSS) has been shown to provide an accurate depiction of soft tissue abnormalities in several rheumatic diseases. ${ }^{1-3}$

Moreover, GSS has been shown to be a useful, safe, and inexpensive tool for the guidance of needle placement during diagnostic and therapeutic invasive procedures. ${ }^{4-6}$

Recently, some studies have demonstrated the ability of power Doppler ultrasonography (PDS) to detect soft tissue hyperaemia, which may be of value in the identification and characterisation of synovitis. $^{7-10}$

Although it has been reported that GSS and PDS may have a useful role in monitoring the treatment of patients with chronic arthritis, ${ }^{61-14}$ evidence is still scarce.

This study aimed at investigating the ability of high resolution GSS and PDS to assess short term soft tissue changes induced by intra-articular steroid injection in the small joints of patients with chronic synovitis.

\section{PATIENTS AND METHODS}

\section{Patients}

Table 1 presents the clinical and demographic features of the patients. All patients presented with clinically active synovitis of a small joint of the hand, wrist, or foot, unresponsive to systemic drug treatment. All patients underwent a sonographic guided intralesional injection with triamcinolone acetonide. The dose of the steroid depended on the joint size, ranging from $10 \mathrm{mg}$ for the small joints of the fingers to $30 \mathrm{mg}$ for the radiocarpal joint. Except for local application of ice after the injection, no other changes in the pre-existing therapeutic regimen were made. No aspiration of synovial fluid was performed, because of the small size of the joints or the prevalence of synovial proliferation on effusion, or both.

\section{Clinical examination}

Clinical examination was carried out by a trained rheumatologist (FS). A visual analogue scale (VAS) for pain (ranging from 0 to 10 ) and a tenderness score (ranging from 0 to 3 ) were used as measures of disease activity.

\section{Sonographic examination}

Patients were examined with an AU5 Harmonic-Esaote Biomedica (Genoa, Italy), using a broadband linear probe with frequency ranging from 10 to $14 \mathrm{MHz}$. Power Doppler settings were standardised with a pulse repetition frequency of $1000 \mathrm{~Hz}$ and a colour-mode frequency of $7 \mathrm{MHz}$. Wall filters were set at the lowest value, while colour gain was increased to the highest value not generating power Doppler signals under the bony cortex. ${ }^{7}$ Each joint was explored for the highest level of expression of signs of synovitis, using a multiplanar examination according to the standard scanning protocol reported in the guidelines for musculoskeletal sonography. ${ }^{15}$ Particular attention was paid to avoiding any pressure on the skin in order to prevent synovial fluid dislocation or local blood flow reduction, or both. No stand off pad was used. The sonographic images showing the most representative features of synovitis were stored for the final assessment. Joint cavity widening and power Doppler signal were evaluated and graded on a semiquantitative scale ranging from 1 to $4: 1=$ normal or minimal degree; $2=$ mild degree; $3=$ moderate degree; $4=$ marked degree.

GSS and PDS examinations were performed independently by two experienced examiners (EF and AF) unaware of the results of clinical examination. The interobserver $\kappa$ values for agreement between the two examiners for the assessment of GSS and PDS findings were respectively 0.868 (standard error $(\mathrm{SE})=0.158)$ and $0.953(\mathrm{SE}=0.159)$ at baseline and 0.853 $(\mathrm{SE}=0.174)$ and $0.901(\mathrm{SE}=0.201)$ at follow up examinations. When the scores assigned by the two examiners did not match, they reached a consensus by re-examining the patient together as proposed by Walther et al. ${ }^{8}$

\section{Follow up examinations}

Clinical and sonographic follow up examinations were carried out 2 weeks after the sonographic guided intralesional injection with triamcinolone acetonide, with particular

\footnotetext{
Abbreviations: GSS, grey scale sonography; PDS, power Doppler
} sonography; VAS, visual analogue scale 
Table 1 Patients' demographic characteristics, clinical diagnoses, anatomical sites injected, dose of triamcinolone acetonide, and baseline and follow up clinical and sonographic scores

\begin{tabular}{|c|c|c|c|c|c|c|c|c|c|c|c|c|c|}
\hline Patient & $\begin{array}{l}\text { Age } \\
\text { (years) }\end{array}$ & Sex & $\begin{array}{l}\text { Anatomical } \\
\text { site }\end{array}$ & Diagnosis & $\begin{array}{l}\text { Dose of } \\
\text { triamcinolone } \\
\text { acetonide }(\mathrm{mg})\end{array}$ & $\begin{array}{l}\text { Baseline } \\
\text { VAS } \\
(0-10)\end{array}$ & $\begin{array}{l}\text { Tenderness } \\
(0-3)\end{array}$ & $\begin{array}{l}\text { GSS } \\
(1-4)\end{array}$ & $\begin{array}{l}\text { PDS } \\
(1-4)\end{array}$ & $\begin{array}{l}\text { Follow } \\
\text { VAS* } \\
(0-10)\end{array}$ & $\begin{array}{l}\text { of after } 2 \text { wee } \\
\text { Tenderness* } \\
(0-3)\end{array}$ & $\begin{array}{l}\text { ks } \\
\text { GSS* } \\
(1-4)\end{array}$ & $\begin{array}{l}\text { PDS* } \\
(1-4)\end{array}$ \\
\hline 1 & 30 & $\mathrm{~F}$ & Wrist & $\operatorname{ReA}$ & 20 & 8 & 2 & 2 & 2 & 0 & 0 & 1 & 1 \\
\hline 2 & 32 & $\mathrm{~F}$ & Wrist & RA & 20 & 8 & 2 & 3 & 3 & 2 & 1 & 2 & 1 \\
\hline 3 & 81 & $M$ & Wrist & CPPD & 30 & 5 & 2 & 4 & 4 & 3 & 1 & 3 & 3 \\
\hline 4 & 82 & $\mathrm{~F}$ & Wrist & RA & 30 & 9 & 3 & 3 & 4 & 1 & 1 & 1 & 2 \\
\hline 5 & 64 & $\mathrm{~F}$ & MTP & RA & 10 & 10 & 3 & 2 & 2 & 4 & 2 & 2 & 2 \\
\hline 6 & 63 & $\mathrm{~F}$ & MTP & RA & 10 & 10 & 3 & 4 & 4 & 4 & 2 & 3 & 2 \\
\hline 7 & 30 & $\mathrm{~F}$ & Wrist & RA & 20 & 7 & 2 & 2 & 3 & 0 & 0 & 1 & 1 \\
\hline 8 & 54 & $\mathrm{~F}$ & $M C P$ & PsA & 10 & 7 & 3 & 2 & 2 & 4 & 2 & 1 & 1 \\
\hline 9 & 55 & $\mathrm{~F}$ & Wrist & RA & 30 & 10 & 3 & 1 & 1 & 4 & 2 & 1 & 1 \\
\hline 10 & 82 & $\mathrm{~F}$ & MCP & RA & 10 & 8 & 3 & 2 & 3 & 0 & 1 & 2 & 1 \\
\hline 11 & 68 & $\mathrm{~F}$ & Wrist & RA & 30 & 9 & 3 & 2 & 3 & 4 & 2 & 2 & 2 \\
\hline 12 & 63 & $\mathrm{~F}$ & Wrist & RA & 30 & 8 & 3 & 4 & 4 & 3 & $\overline{1}$ & 3 & 2 \\
\hline 13 & 62 & $\mathrm{~F}$ & Wrist & RA & 30 & 5 & 2 & 2 & 4 & 3 & 1 & 2 & 2 \\
\hline 14 & 37 & $\mathrm{~F}$ & PIP & PsA & 10 & 10 & 3 & 3 & 4 & 1 & 1 & 2 & 1 \\
\hline 15 & 70 & $M$ & Wrist & CPPD & 30 & 8 & 3 & 2 & 1 & 4 & 2 & 2 & 1 \\
\hline 16 & 70 & $\mathrm{~F}$ & Wrist & CPPD & 30 & 8 & 3 & 2 & 3 & 1 & 1 & 1 & 1 \\
\hline 17 & 30 & $M$ & DIP & PsA & 10 & 8 & 3 & 2 & 4 & 0 & 0 & 1 & 1 \\
\hline 18 & 31 & $M$ & DIP & PsA & 10 & 6 & 3 & 2 & 2 & 2 & 1 & 1 & 1 \\
\hline 19 & 30 & $M$ & Wrist & PsA & 20 & 8 & 3 & 3 & 4 & 0 & 0 & 1 & 1 \\
\hline 20 & 55 & $\mathrm{~F}$ & Wrist & RA & 20 & 6 & 2 & 3 & 3 & 0 & 1 & 2 & 1 \\
\hline Median & 58,5 & $15 \mathrm{~F} / 5 \mathrm{M}$ & & & & 8 & 3 & 2 & 3 & 2 & 1 & 2 & 1 \\
\hline
\end{tabular}

attention being paid to reproducing the baseline scanning approach.

\section{Statistical analysis}

All the recorded clinical and sonographic findings are qualitative variables. Significance testing was performed using the Wilcoxon signed rank test. A p value of $<0.05$ was considered significant. The relationship between the clinical and sonographic (GSS and PDS) findings was analysed using Spearman's rank correlation test. Statistical analysis was performed using MedCalc software (version 6.0) for Windows.

\section{RESULTS}

Sonographic guided intra-articular injections were successfully carried out in all patients (table 1 ).

At baseline clinical examinations, the median VAS value was $8(95 \%$ confidence intervals (CI) 7 to 9$)$, while the median tenderness value was $3(95 \%$ CI 2 to 3 ). Baseline sonographic examinations detected clearly evident morphological (joint cavity widening) and perfusional (power Doppler signal) signs of synovitis in all patients except patient number 9. The median GSS score was 2 (95\% CI 2 to 3 ), while the median PDS score was 3 (95\% CI 2 to 4 ).

At follow up clinical examinations, both VAS and tenderness scores had improved and a significant decrease of the VAS score $(p<0.01)$ and tenderness scores $(p<0.01)$ was found. A significant change was also detected for the sonographic findings between baseline and follow up values of the GSS $(\mathrm{p}<0.01)$ and PDS scores $(\mathrm{p}<0.01)$.

In $14 / 20(70 \%)$ patients reduction of both GSS and PDS scores was found. Figure 1 shows representative sonographic images of baseline and follow up examinations of a patient with rheumatoid arthritis, documenting the decrease of the joint cavity widening and of the power Doppler signals. Figure 1 also shows a mild persistent increase of perfusion at the midcarpal joint as compared with the lack of any residual signs of active inflammation in the radiocarpal joint. A possible explanation of such a difference may be that in this patient there was no communication between radiocarpal and midcarpal joint, which is relatively common in patients with rheumatoid arthritis.

Four of $20(20 \%)$ patients (patients numbers 1, 7, 17, and 19) achieved complete remission of pain and the disappearance of sonographic features of synovitis (fig 2).

In $3 / 20$ (15\%) patients (patients numbers 10,11 , and 13), both clinical and PDS scores were reduced, while no changes of the GSS score were detected at follow up examinations. Three of 20 (15\%) patients (patients numbers 5, 9, and 15) presented with no GSS and PDS score changes at follow up examinations.

GSS score reduction correlated with tenderness score improvement (Spearman's $r_{\mathrm{s}}=0.636 ; \mathrm{p}=0.006$ ), while no significant correlation between GSS score reduction and VAS score improvement was found (Spearman's $r_{\mathrm{s}}=0.457$; $\mathrm{p}=0.046)$. PDS score reduction correlated with both VAS and tenderness score improvements: Spearman's $r_{\mathrm{s}}=0.602$; $\mathrm{p}=0.009$ and Spearman's $r_{\mathrm{s}}=0.670 ; \mathrm{p}=0.003$, respectively.

\section{DISCUSSION}

PDS has been shown to be a reliable method for assessing synovitis in patients with chronic arthritis. ${ }^{8}{ }^{12-14}$ At present, however, there is little evidence to support the ability of PDS to demonstrate synovial perfusion changes induced by steroid treatment. ${ }^{11} 13$

The only previous comparable study on PDS monitoring of intra-articular steroid injection treatment included seven patients with knee synovitis, five patients with rheumatoid arthritis, one patient with psoriatic arthritis, and one patient with calcium pyrophosphate dihydrate deposition disease. ${ }^{11}$ After a mean time of 7.4 days (range 4-15) clinical response was defined as "good" in six of seven patients.

The potential role of PDS in treatment monitoring was also explored by Stone et al in patients with rheumatoid hand synovitis. ${ }^{13}$ In that study, however, four patients received intravenous methylprednisolone (125 mg) for three consecutive days and the remaining eight patients received $20 \mathrm{mg}$ oral prednisolone. The change in PDS signal in individual joints was described as "dramatic". 

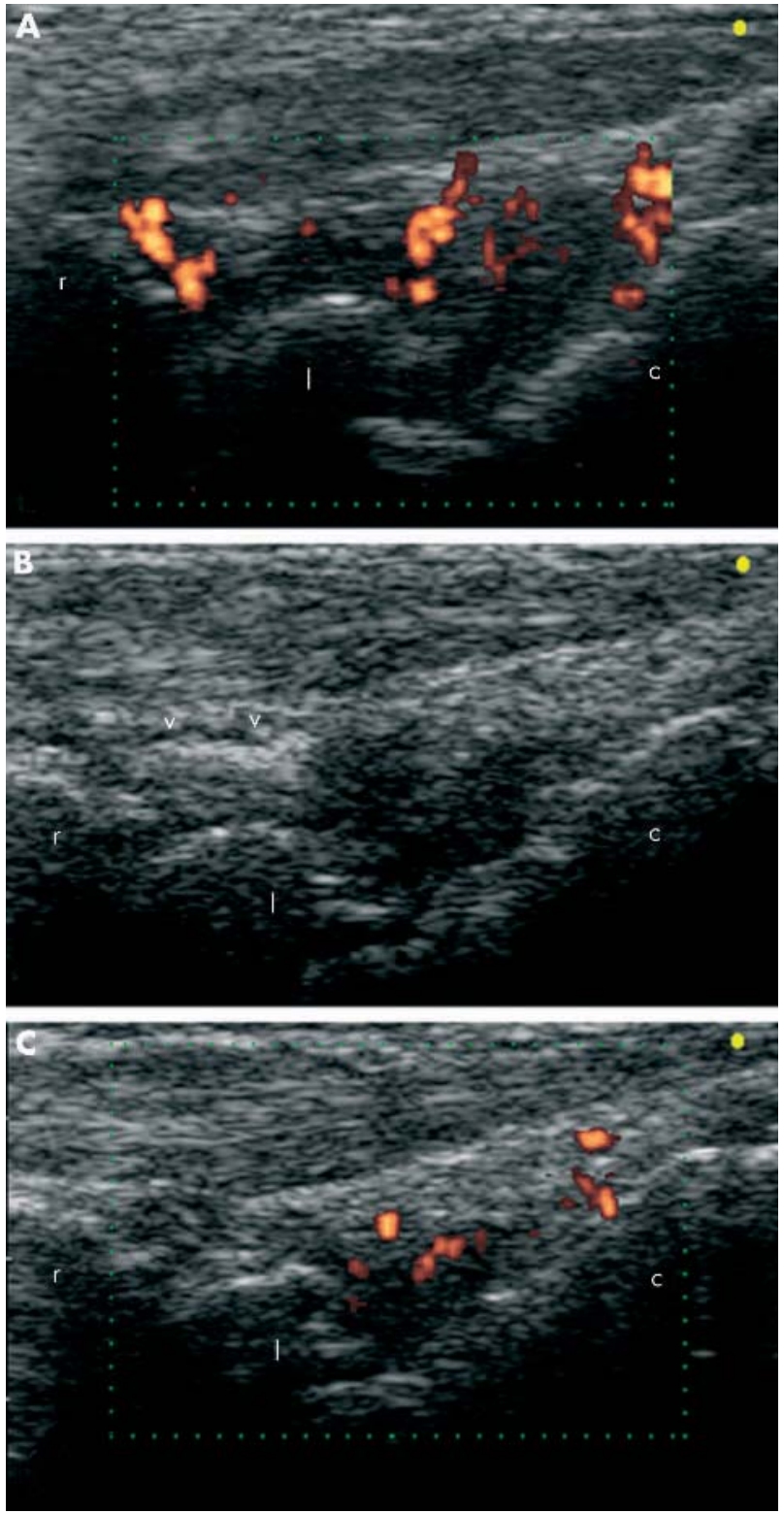

Figure 1 (A, B) Baseline ultrasound examination on longitudinal dorsal scan of the wrist joint of an 82 year old patient with rheumatoid arthritis (patient number 4). An intra-articular injection of triamcinolone acetonide $(30 \mathrm{mg}$ ) was performed under sonographic guidance. Triamcinolone appeared as an echogenic area within the radiocarpal joint cavity (V). (C) Follow up ultrasound examination detected a clearly evident decrease of both joint cavity widening (GSS score reduced from 3 to 1) and power Doppler signals (PDS score reduced from 4 to 2). $\mathrm{c}$, capitate bone; l, lunate bone; $r$, radius.

To the best of our knowledge, this is the first study that provides statistical evidence of the value of sonography in the detection of GSS and PDS changes induced by intra-articular steroid injection treatment in the small joints of patients with chronic arthritis.

Our data indicate that such changes can be clearly seen even after a very short term follow up. The reduction of PDS signals appears to be related to the improvement of symptoms of synovitis (pain and tenderness). Of interest, is that PDS can detect persistently active synovitis that may be underestimated by clinical assessment.

Sonography is safe, inexpensive, not invasive, and well tolerated. No other imaging modality shares all these
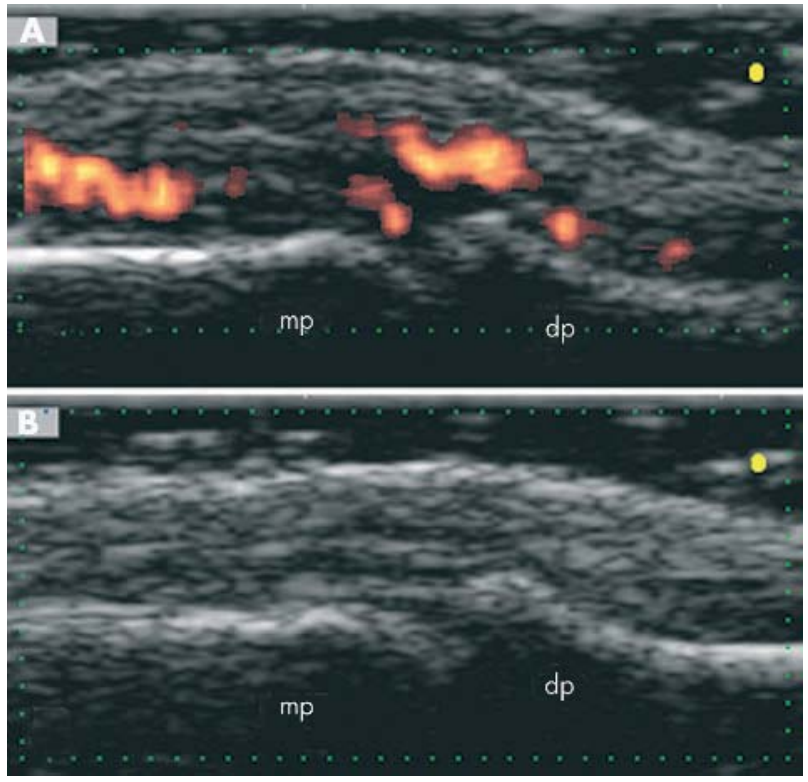

Figure 2 A 30 year old patient with psoriatic arthritis (patient number 17) presented at baseline clinical examination with a severe pain of the distal interphalangeal joint of his left second finger (VAS score 8; tenderness score 3). At follow up clinical examination the patient had complete remission of pain (VAS score 0; tenderness score 0). (A) Baseline ultrasound examination on longitudinal dorsal scan detected evident signs of active synovitis: joint cavity widening (GSS score 2) and intra-articular power Doppler signals (PDS score 4). A sonographic guided injection with $10 \mathrm{mg}$ of triamcinolone acetonide was performed. (B) Two weeks after the injection an ultrasound examination performed at the same plane of scanning showed the disappearance of both GSS (score 1) and PDS (score 1) findings. dp, distal phalanx; mp, middle phalanx.

features. Our preliminary report supports the view that GSS and PDS may be regarded as useful adjunctive tools for assessing short term soft tissue changes after intra-articular injection treatment with triamcinolone acetonide in the small joints of patients with chronic synovitis. Further studies are obviously needed to better define the role of GSS and PDS in monitoring treatment and to determine their impact on therapeutic decisions.

\section{ACKNOWLEDGEMENTS}

Supported by Università degli Studi di Ancona grant No 1104 of 2903-2001.

\section{Authors' affiliations}

E Filippucci, A Farina, F Salaffi, W Grassi, Department of Rheumatology, Università Politecnica delle Marche, Italy

M Carotti, Department of Radiology, Università Politecnica delle Marche, Italy

Correspondence to: Dr W Grassi, Clinica Reumatologica, Universitò Politecnica delle Marche, Ospedale A. Murri, Via dei Colli, 52. 60035 Jesi (Ancona), Italy; reuman@unian.it

Accepted 21 July 2003

\section{REFERENCES}

1 Wakefield RJ, Gibbon WW, Conaghan PG, O'Connor P, McGonagle D Pease $\mathrm{C}$, et al. The value of sonography in the detection of bone erosions in patients with rheumatoid arthritis: a comparison with conventional radiography. Arthritis Rheum 2000;43:2762-70.

2 Grassi W, Filippucci E, Farina A, Cervini C. Sonographic imaging of tendons. Arthritis Rheum 2000:43:969-76.

3 Balint PV, Kane D, Wilson H, Mclnnes IB, Sturrock R. Ultrasonography of entheseal insertions in the lower limb in spondyloarthropathy. Ann Rheum Dis 2002;61:905-10. 
4 Koski JM. Ultrasound guided injections in rheumatology. J Rheumatol 2000;27:2131-8.

5 Grassi W, Farina A, Filippucci E, Cervini C. Sonographically guided procedures in rheumatology. Semin Arthritis Rheum

2001;30:347-53.

6 Grassi W, Farina A, Filippucci E, Cervini C. Intralesional therapy in carpal tunnel syndrome: a sonographic-guided approach. Clin Exp Reumatol 2002;20:73-6.

7 Rubin JM, Adler RS, Fowlkes JB, Spratt S, Pallister JE, Chen JF, et al. Fractional moving blood volume: estimation with power Doppler US. Radiology 1995; 197:183-90.

8 Walther M, Harms H, Krenn V, Radke S, Faehndrich TP, Gohlke F. Correlation of power Doppler sonography with vascularity of the synovial tissue of the knee joint in patients with osteoarthritis and rheumatoid arthritis. Arthritis Rheum 2001:44:331-8.

9 Szkudlarek M, Court-Payen M, Strandberg C, Klarlund M, Klausen T, Østergaard M. Power Doppler ultrasonography for assessment of synovitis in the metacarpophalangeal joints of patients with rheumatoid arthritis. A comparison with dynamic magnetic resonance imaging. Arthritis Rheum 2001;44:2018-23.
10 Schmidt WA Volker L, Zacher J, Schlafke M, Ruhnke M, Gromnica-lhle E. Colour Doppler ultrasonography to detect pannus in knee joint synovitis. Clin Exp Rheumatol 2000;18:439-44.

11 Newman JS, Laing TJ, McCarthy CJ, Adler RS. Power Doppler sonography of synovitis: assessment of therapeutic response-preliminary observations. Radiology 1996;198:582-4.

12 Hau M, Schultz H, Tony HP, Keberle M, Jahns R, Haerten R, et al. Evaluation of pannus and vascularization of the metacarpophalangeal and proximal interphalangeal joints in rheumatoid arthritis by high-resolution ultrasound (multidimensional linear array). Arthritis Rheum 1999;42:2303-8.

13 Stone M, Bergin D, Whelan B, Maher M, Murray J, McCarthy C. Power Doppler ultrasound assessment of rheumatoid hand synovitis. J Rheumatol 2001;28:1979-82.

14 Hau M, Kneitz C, Tony H-P, Keberle M, Jahns R, Jenett M. High resolution ultrasound detects a decrease in pannus vascularisation of small finger joints in patients with rheumatoid arthritis receiving treatment with soluble tumour necrosis factor $\alpha$ receptor (etanercept). Ann Rheum Dis 2002;61:55-8.

15 Backhaus M, Burmester G-R, Gerber T, Grassi W, Machold KP, Swen WA, et al. Guidelines for musculoskeletal ultrasound in rheumatology. Ann Rheum Dis 2001;82:641-9. 